\title{
AN EXTREMELY RARE RECESSIVE HEREDITARY SYNDROME INCLUDING CEREBELLAR ATAXIA, OLIGOPHRENIA, CATARACT, AND OTHER FEATURES
}

\author{
BY
}

HUGH GARLAND and DOREEN MOORHOUSE

\author{
From the Department of Neurology, General Infirmary at Leeds
}

Under the title of "Nouvelle maladie familiale caractérisée par une cataracte congénitale et un arrêt du developpement somato-neuropsychique " a paper was written by Marinesco, Draganesco, and Vasiliu in 1931 describing four siblings clearly suffering from the same disorder, a syndrome which had not been previously described. Sjögren (1950) reported 14 similar patients, discovered after painstaking search throughout Sweden, and he believed this to be only the second time the syndrome had been observed; he, however, was able to prove beyond doubt that this is a hereditary disorder, due to a single autosomal recessive gene and frequently resulting from consanguinaous marriage.

In 1933 one of us was asked by Professor C. W. Vining to examine two children then under his care. They were first cousins apparently suffering from an identical and congenital syndrome. There was a remarkable history of consanguinity in the family but at that time it was not clear whether the disorder, in all its aspects, was stationary, and it was difficult to assess the intellectual level of the patients. They were not seen again until one of them was referred to us in 1951. It was then possible to make a more accurate clinical assessment, and both were admitted to the Neurological Department of the General Infirmary at Leeds for more detailed investigation in September, 1952.

\section{Case Reports}

Case 1.-A boy was born on December 24, 1925. He was a full term child weighing $8 \frac{1}{2} \mathrm{lb}$. $(3 \cdot 8 \mathrm{~kg}$.) and the fifth of seven siblings. He was never jaundiced. It was noted at 3 weeks that he could not suck normally, he was late in sitting up, but he learned to crawl quickly. Defective speech appeared at about 9 months and was slow, but he always tended to be talkative. He was quick tempered and liable to cry but was said to play normally; he never had convulsions and was clean in his habits at 1 year. When examined by one of us at the age of 6 , he had a slow and grossly dysarthric, almost unintelligible, speech. His mouth was always open, with constant salivation. He was unable to walk, but could stand alone against a wall (Fig. 1) and attempted to walk with support. All the limbs were grossly ataxic, but there was no obvious dystonia or reflex change and the plantar responses were flexor. At this time the mother's general impression was that he was improving.

He was more fully investigated in September, 1952, when his height was $5 \mathrm{ft} .6$ in. $(165 \mathrm{~cm}$.) and weight $7 \mathrm{st} .8 \mathrm{lb}$. (48 kg.). His general health had always been excellent; he had whooping cough at 5 and scarlet fever at 7 . He started to shave at 16 , and shaved daily ; hair distribution was normal. During examination he was very cooperative, asking many questions particu- $\stackrel{\varnothing}{\varrho}$ larly with regard to possible treatment. He was fondo of going out in a wheel-chair and of listening to the wireless. He was able to feed himself with a spoon and to dress himself, apart from fastening buttons.

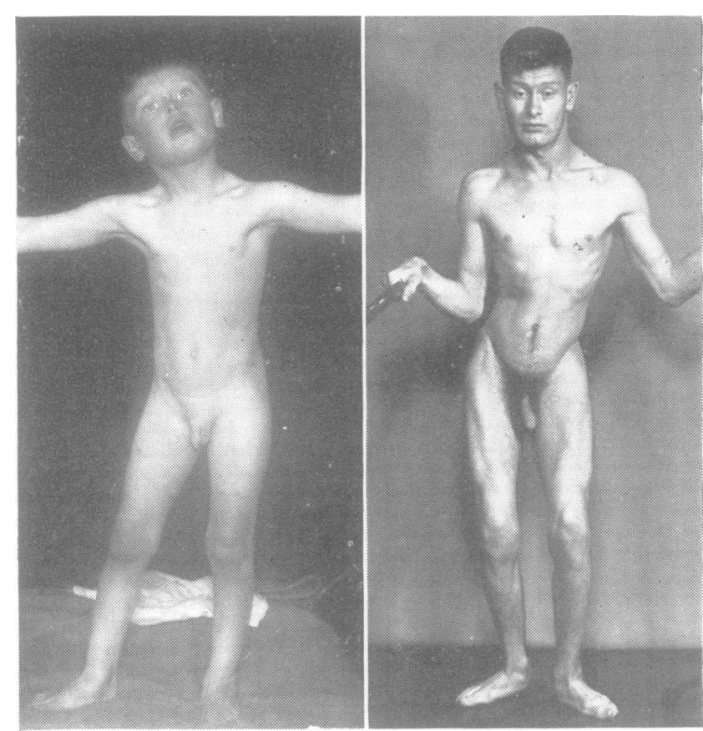

Fig. 1.-On the left Case 1 aged 6 , and on the right the same patient aged 27. 
His usual mood was euphoric, but he was easily upset. Speech was slow and so slurred as to be almost unintelligible. The fundi could not be seen because of bilateral cataract; he was able to count fingers at about $3 \mathrm{ft}$. There was a continuous coarse nystagmus in all directions, with a rotatory element, eye movements being full apart from an inability to converge. The pupils were large but reacted normally to light. Although there was no obvious facial weakness he had difficulty in showing his teeth and was unable to whistle. He was right-handed. His grip was good and equal on both sides, indeed there was no obvious muscular weakness but a striking feature was the widespread firmness of the muscles, visible in Fig. 1. Ordinary methods of testing demonstrated no dystonia in the arms but the outstretched hands were held in a hypotonic attitude. Alternating movements at both wrists were very defective and there was gross ataxia of a cerebellar type in the finger-nose test. There was some limitation of extension at the knee joints, with slight genu valgum and some increase of tone in the legs ; there was gross ataxia of a cerebellar type in the heel-knee test. All the tendon reflexes were extremely brisk, the abdominal reflexes present, and the plantar responses equivocal. He was unable to walk alone and the gait was slow and very ataxic. There was no sensory loss of any kind. There was a constant tachycardia (about 90 per min.), blood pressure $160 / 100 \mathrm{~mm}$. $\mathrm{Hg}$, slight lower dorsal scoliosis, and a deformity of the right fourth and fifth toes.

Electro-encephalography (Dr. M. J. Parsonage).-The record contained a considerable amount of artefact mainly due to eye movement. Basically it was of low voltage but showed no abnormal activity at any stage.

Psychometry (Mr. D. R. Martin).-Throughout the examination the patient was friendly and tried hard, but visual and motor disabilities made the testing difficult. On the Kent Oral Emergency Scale (scale D) he scored 13. His mental age was 8 years (I.Q. about 55). On the Wechsler-Bellevue Intelligence Scale Form I (verbal scale only) the I.Q. was 67. There was a generai impression that with special training the patient would improve in ability although functioning at the feebleminded level.

Ophthalmic Examination (Mr. J. Foster).-There was a bilateral cataract composed of minute dots, occupying the adult as well as the embryonic nucleus, thinner at the centre than at the edges and showing well marked water clefts. The fundi could not be clearly seen.

Electrocardiography (Dr. I. Macpherson).-The record showed low $\mathrm{T}$ waves and slight depression of the S-T segments in leads 2, 3, and V6, suggesting early left ventricular preponderance, in keeping with slight left ventricular hypertrophy.

Radioscopy showed no abnormality of the skull.

Case 2.-A girl was born on January 16, 1928, and was the seventh of nine siblings. She was a full-time child, delivered normally and weighing $8 \mathrm{lb}$. $(3.6 \mathrm{~kg}$.) ; she was never jaundiced. The parents did not realize there was any abnormality until it was noticed that she would

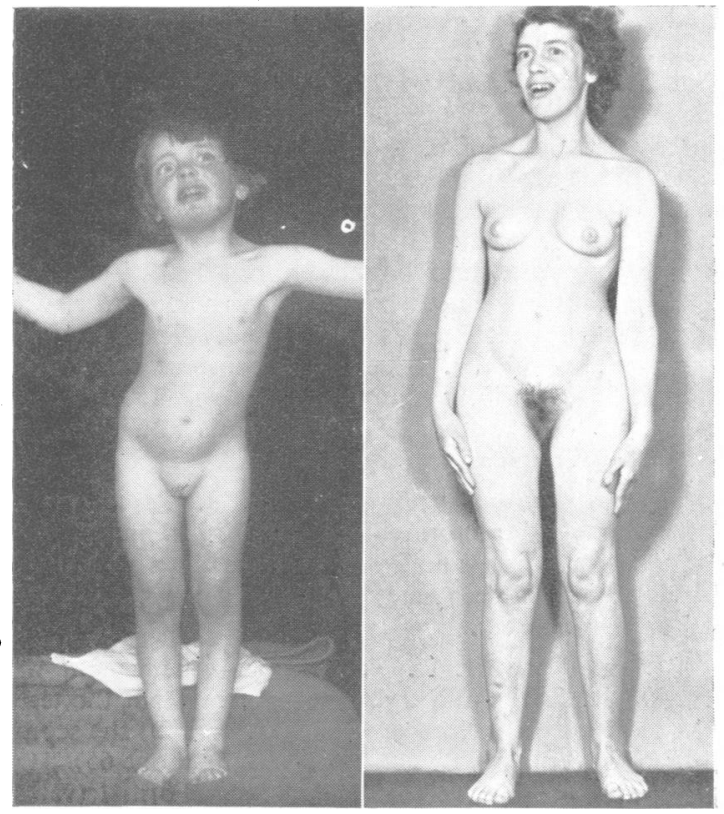

FIG. 2.-Case 2 at 5 years and the same patient aged 24 .

not sit up or try to crawl at 9 months. She was clean in her habits at 1 year, but attempted to talk only at 3, and about this time she had a single convulsion. At 5 years she was unable to walk unaided, the gait being very ataxic. It was thought that distant vision was defective and there was continuous nystagmus with a rotatory element ; speech was very limited and grossly dysarthric. There were no reflex changes, the plantar responses being flexor. She was a shy child, easily annoyed and often crying. The mouth was usually open (Fig. 2).

In September, 1952, she weighed 7 st. $1 \mathrm{lb}$. $(44.5 \mathrm{~kg}$.) and was $5 \mathrm{ft}$. $(150 \mathrm{~cm}$.) tall. She was almost unable to close the lips and had a constant and fatuous grin (Fig. 2). She was euphoric, very easily amused, cooperative, and had an excellent memory; she remembered Professor Vining, whom she had not seen for 20 years, though he had forgotten her. Speech was slow, very slurred, and similar to that of her first cousin (case 1). but she was much more intelligible. She was able to dress and feed herself. She had enjoyed excellent health, having only suffered from measles, whooping-cough, and chickenpox. Menstruation started at 14 and was regular; hair distribution was normal and mammary development full. The right fundus could not be seen because of cataract ; there had been a left capsulotomy on August 7, 1952, and she could count fingers at $2 \mathrm{ft}$. The pupils were large and equal and reacted normally to light, but she was unable to converge and there was continuous gross nystagmus in all directions. She was right-handed. There was no weakness of the arms but the outstretched hands were held in a hypotonic posture. Alternating movements at the wrists were very defective 
and there was gross ataxia of the cerebellar type in the finger-nose test. There was no weakness of the legs, but tone was slightly increased and there was gross cerebellar ataxia in the heel-knee test. All the tendon jerks were very brisk, the abdominal reflexes present and the plantar responses undoubtedly extensor. The muscles in this patient did not show the same firmness as in case 1. She was able to stand unsupported and could jump and hop on either foot rather clumsily. She walked on a broad base and was very ataxic, with a tendency to fall unless supported. There was no sensory abnormality. There was constant tachycardia (about 96 per min.) ; blood pressure was 150/100 mm. $\mathrm{Hg}$. There was a dorso-lumbar scoliosis and deformity of both fifth fingers and toes.

Electro-encephalography (Dr. M. J. Parsonage).There was no abnormality during 15 minutes' continuous recording, and basically the record was of the low-voltage-high-frequency type containing no activity of alpha frequency.

Psychometry (Mr. D. R. Martin).-The patient was cheerful, friendly, and trying hard throughout the tests. On the Kent Oral Emergency Scale (scale D) she scored 18. Her mental age was 10 years (I.Q. about 65). On the Wechsler-Bellevue Intelligence Scale Form 1 (verbal scale only) her I.Q. was 61. The intellectual efficiency was at the feeble-minded level, though she gave a general impression of being more intelligent than this; and it was felt that she might improve with special education.

Air-encephalography.-Air, $40 \mathrm{ml}$., was introduced intrathecally and revealed no abnormality of the ventricular system. The cerebrospinal fluid was normal in all respects and there was no radiological abnormality of the skull.

Ophthalmic Examination (Mr. J. Foster).-The patient was first examined in 1951, when she was found to have a fine punctate bilateral cataract consisting of a multitude of tiny dots, of the type which used to be regarded as associated with glandular dyscrasia. Capsulotomy was carried out on August 7, 1952 ; it was then found that the optic disc was pale but it was impossible to see details of the fundus clearly because of nystagmus and it was thought that the latter was largely responsible for the poor vision.

Electrocardiography (Dr. I. Macpherson).-There were small Q.R.S. complexes in lead 1, almost certainly due to a vertical heart position, but the record contained no other abnormality.

\section{Pedigree of Cases 1 and 2}

Fig. 3 shows the very remarkable family history of the two patients described (V, 7 and 14). It will be seen that they are the descendants of the same pair of great-great-grandparents. The pedigree shows that consanguineous marriages occurred four times in two generations (III and IV), that the mothers (IV, 1 and 2) of the two patients were sisters and that each of the four parents (III, 1, IV, 1, 2, and 6) was related to the other three. This pedigree has been constructed through the help of the three sisters (IV, 1, 2, and 4) and

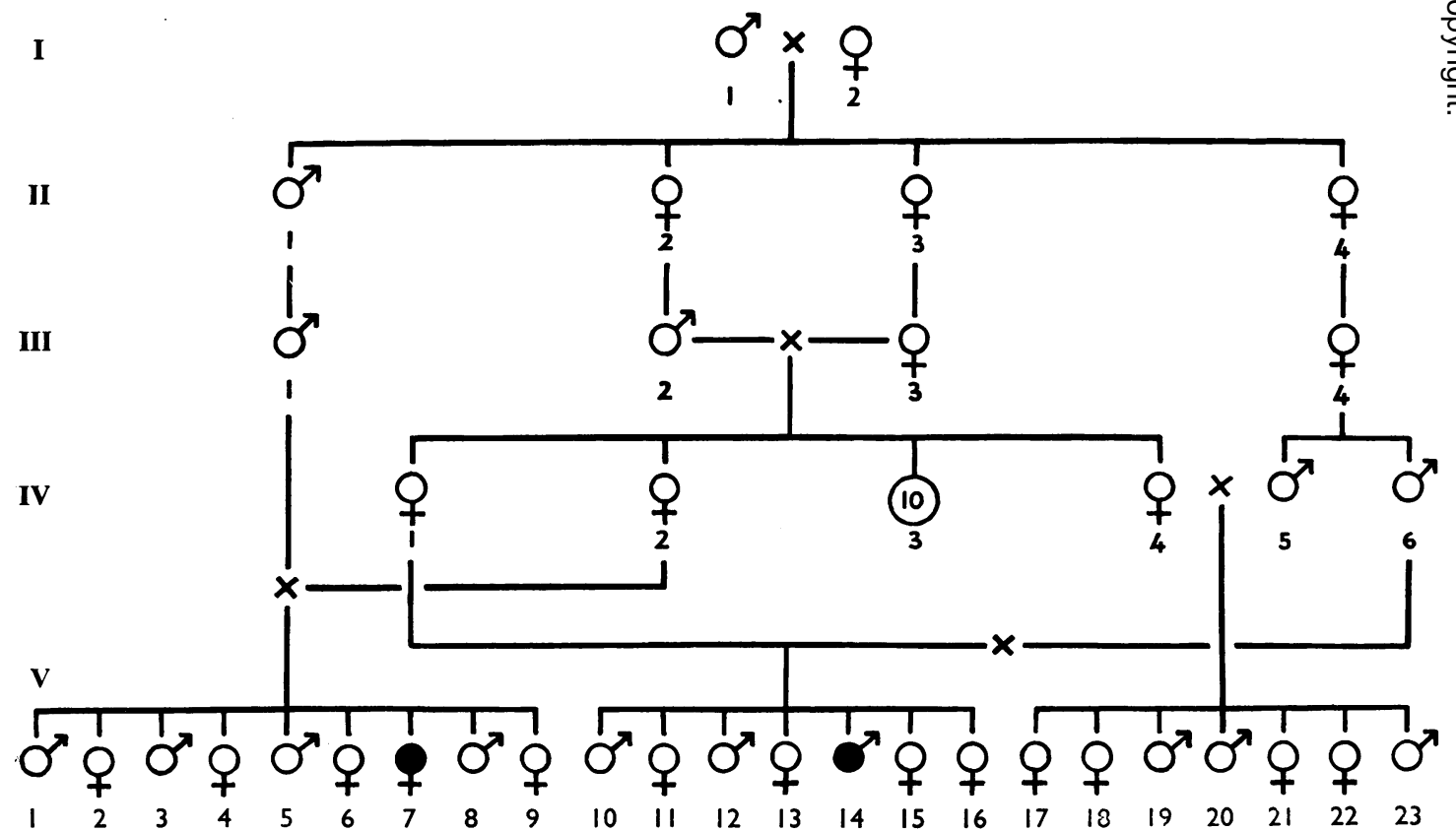

FIG. 3.-Pedigree of cases 1 and 2. 
their husbands. One sister (IV, 4) married a second cousin (IV, 5) ; there are seven children (V, 17-23) who are all alive and well. The circle (IV, 3) represents 10 siblings all said to be normal ; as far as we know there were no consanguineous marriages, but most are married and have normal children. The sister (IV, 1) also married a second cousin (IV, 6) who is the brother of the man (IV, 5) who married her sister (IV, 4). There were seven children $(\mathrm{V}, 10-16)$ of this marriage ; the fifth is case 1 and the second and sixth (females, V, 11 and $15)$ are alive and well. The first (male, V, 10) died in convulsions after a few days; he weighed $14 \mathrm{lb}$. $(6.3 \mathrm{~kg}$.) and .probably had a birth injury. The third (male, $\mathrm{V}, 12$ ) died at 7 months in convulsions, the fourth (female, $V, 13$ ) died at 3 months also in convulsions, and the seventh (female, V, 16) died at 2 weeks of an umbilical haemorrhage. The sister (IV, 2) married a man (III, 1) considerably older than herself who was a first cousin of both her parents (III, 2 and 3), who were themselves first cousins ; they had nine children $(\mathrm{V}, 1-9)$, of which case 2 is the seventh, all the others being alive and well. Further details of generations I to IV are not known but the persons interviewed are satisfied that there are no others in the family similarly affected, nor are they aware of any examples of cataract or of mental deficiency. It is, of course, impossible to make any pronouncement about the four siblings in generation $\mathrm{V}$ who died in infancy, but of the remaining 12 in generation V, 1-16, only two are affected. There are no affected persons in the sibship V, 17-23 but here the recessive factor may not have been carried by both parents. The incidence of consanguinity in this family is particularly striking since they are not found in an isolated village community but all lived in sizeable (and different) industrial towns in the West Riding of Yorkshire, to which generation III appears to have moved from Staffordshire.

\section{Comments on Cases 1 and 2}

It will be generally accepted that the two patients described are suffering from the same disorder. Perhaps the most striking feature is the congenital and widespread ataxia, of cerebellar type, associated with gross dysarthria and nystagmus. We are satisfied, despite the suggestions of the parents, that this aspect of the syndrome is stationary, and the history suggests very strongly that the cerebellar defect is of developmental origin. There is no doubt that both patients are mentally backward. A precise assessment is impossible because of the absence of education together with the visual, speech, and motor defects, but the general impression even in childhood has been that intelligence is not so inferior as a superficial examination would suggest. Both suffer from cataract of an unusual and similar type and there is no doubt that this has been progressive. It was not detected by one of us on routine examination in childhood, though it was thought that the vision in case 2 was not normal at 5 years and she became blind at an earlier age than her cousin (case 1). It would seem likely that he will become blind unless or until he is suitable for capsulotomy. We are satisfied that there is no defect of sensation, but there is evidence of pyramidal tract involvement in both patients, as shown by very brisk tendon jerks, increase of tone in the legs, and undoubted extensor plantar responses in case 2. Both are undersized and show minor skeletal deformities, including scoliosis, genu valgum, limitation of extension of the knee joints, and anomalies in the fingers and toes, with electroencephalograms which are normal, persistent tachycardia, and moderate hypertension. Both enjoy good health and in neither is there evidence of endocrine dysfunction. There are only small differences between the two and these are mostly of degree.

\section{Analysis of Previous Reports}

Marinesco and others (1931) realized that four siblings were suffering from the same disorder, which had probably not been described before, but unfortunately their paper contained serious errors. They described two normal (married) Roumanian peasants. There had been 10 pregnancies, including one stillborn child and three others dying in infancy. Of the remaining six, two were examined and said to be normal, and case histories of the other four (one male, three females) were recorded, but there was an unfortunate reference later in the paper to five similarly affected persons (one male, four females); who the fifth affected female was remains a mystery. To add to the confusion, Sjögren (1950) in referring to the Roumanian paper stated that "the disease occurred in five sibs (four boys and one girl)". At this late stage it would seem reasonably certain that the Roumanian sibship consisted of a stillbirth, three children who died in infancy, two unaffected males, and four affected siblings (one male, three females), or that of six siblings who survived beyond the first year, four were affected with the same disorder. In this family all four affected persons were noticed to have failing vision in the third year, in each proceeding to blindness from cataract within a year or two. In the eldest affected person (female, aged 18) the cataract was noted to be densest in the middle, with 
a peripheral clear ring. In none was the cataract treated. All four were considerably undersized, as is well shown in photographs. They showed notable clumsiness of all four limbs, with signs characteristic of a cerebellar defect and with muscular hypotonia. At the time of examination (aged 18, 17, 8, and 4) all showed brisk tendon and abdominal reflexes, with flexor plantar responses, and it was thought that the cerebellar defect was complicated by a pyramidal disturbance. This family had been under observation for several years, and there was a suggestion that in two patients the neurological syndrome might have been progressive. All four showed a well marked mental defect. A girl of 18 did not know her right hand from her left, and the mental state in a boy of 17 was said to be even worse, but the mentality of the other two was not described in detail. Three of the four were said to show old rachitic deformities and $x$-ray changes were noted in the terminal phalanges of two. A biopsy was carried out on the right frontal cortex in one patient (female, aged 8), and the histological changes were described in considerable detail, showing atrophy of ganglion cells and a paucity of nerve fibres. For some reason, which is not clear, serum calcium estimations were carried out on six members of the family, and in one affected child the level was certainly low $(6.9 \mathrm{mg} . \%)$ but it was also low $(7.7 \mathrm{mg} . \%)$ in the normal father (incorrectly referred to by Richards (1950) as the mother) and in one of the normal brothers $(6.7 \mathrm{mg} . \%)$ and was slightly low in another affected sibling $(8.5 \mathrm{mg} . \%)$. It seems highly probable that these figures are either inaccurate or irrelevant. Although the authors recognized that four members of a family were suffering from a disorder which they believed to be unique, it apparently did not occur to them that it might have resulted from a hereditary factor, and they were fairly convinced that the syndrome resulted from an endocrine dyscrasia, drawing some parallel with cretinism. They were also somewhat minded to invoke vitamin deficiency, though admitted that it was difficult in that case to explain away the normal members of the family. Whether or not the parents were blood relations will presumably never be known.

Sjögren (1950), after a preliminary report in 1947 , agreed that the Roumanian family had been unique, but then described a group of similar patients. He had found 14 affected persons in three families. Family A consisted of five generations, and in the third generation there were two consanguineous marriages (A2 and A3). There were 10 children of the marriage A2 (three males, seven females), of whom one male and one female were affected, and nine children of the marriage A3 (two males, seven females), of whom two females $Z$ were affected. The parents of family Al were a normal male from A2 and a normal female from A3 ; their marriage resulted in nine children (three males, six females) of whom three females were 0 affected. In the three sibships, $\mathrm{A} 1, \mathrm{~A} 2$, and $\mathrm{A} 3$, therefore, there were seven affected persons (one male, six females) all the results of consanguineous marriages, all the parents of affected persons being first cousins. Sjögren's second pedigree (family B) $\vec{\Rightarrow}$ also refers to five generations. In the fourth there is a sibship of five (three males, two females) with one affected male, and in the fifth generation there is a sibship of 10 (six males, four females) in which three males and one female were affected. Again, all the affected persons resulted from marriage o between first cousins. In family $\mathrm{C}$ there were two affected siblings (one male, one female). The parents were said to be normal and there was no evidence of consanguinity. No further details were given.

Unfortunately only four of the 14 had been personally examined (one in each of families $A$ and $B$ and the two in family $C$ ) though there seems to be $\overline{0}$ ? little doubt that all 14 suffered from the sam $\overrightarrow{0}$ disorder. Of the four personally examined twळ were males and two females. The first (female aged 43) had been under observation for almost $2 \theta \frac{3}{3}$ years. She showed a mental defect which was nod progressive, an ataxic gait which was slowly pros. gressive, blindness from cataract when first seenō widespread weakness of the limbs with moderate hypotonia and marked cerebellar ataxia, dysarthria, and nystagmus. The tendon reflexes were brisk and the plantar responses extensor. She was undersized and showed scoliosis and bilateral talipes. The second (male, aged 38) had also been under observation for many years. He was known to have a severe mental defect from infancy, with congenital cataract progressing to blindness, and there was widespread weakness of the limbs, with cerebellar ataxia, nystagmus, and dysarthria. The tendon reflexes were brisk in 1931 and diminished in 1948 ; the abdominal reflexes were normal and the plantar responses were equivocal in 1931 and extensor in 1948. He was undersized and showed a kyphoscoliosis and talipes, with vasomotor changes in the feet. The third (female, aged 25) had shown a severe mental defect from birth, lifelong disturbance of gait, and bilateral cataract first diagnosed at the age of 6 . She was undersized and showed widespread weakness of the limbs with cerebellar ataxia, dysarthria, and nystagmus. The tendon reflexes were normal and the plantar responses 
extensor. She had a pronounced kyphosis and talipes. The fourth (male, aged 22) was mentally defective from birth, with bilateral cataract first diagnosed at the age of 3 . He also had widespread cerebellar ataxia, dysarthria, and nystagmus. The plantar responses were extensor and the tendon reflexes brisk. He was undersized and showed kyphosis and talipes.

Richards (1950) was familiar with the Roumanian paper and with the preliminary report of Sjögren (1947). He described two patients with cataract, mental deficiency, and a neurological disorder, being the only two so affected in a population of 2,000 mentally defective persons. The first case was a female, aged 11 years who was illegitimate and for whom no family history was available, though there was a normal younger sibling. This child had been under observation for nearly eight years. A central lens opacity had been detected at the age of 6 and the cataract was subsequently progressive ; there was a strabismus but (presumably) no nystagmus. At all stages speech was said to be normal. The I.Q. (Terman-Merrill) was 68 . The neurological picture is rather confused; at $3 \frac{1}{2}$ years the child was said to have total areflexia, but at 10 only the triceps jerks were absent. The plantar responses were extensor. She was said to have good muscular power, slight intention tremor, but a very unsteady gait. The second case was a male, first seen at 35 and finally described at 47 . He was not the result of a consanguineous marriage and there was a twin of the same sex who died at 7 months. He was said to have learned to read quite well but no attempt had been made to assess the level of intelligence in early life ; later, as an adult, his mental age was assessed at 10 years. He was under-height, almost blind from cataract and choroiditis, with total areflexia and extensor plantar responses, and there was a slight intention tremor. Although it is admitted that these two patients showed cataract, a mental defect, and a neurological syndrome, it is felt that there are so many differences between these patients and those described by Marinesco and others (1931), Sjögren (1950), and ourselves that it is possible these are examples of a different syndrome and, indeed, there is nothing to show that either was suffering from a genetic abnormality. We therefore do not propose to discuss these two patients further.

\section{Discussion}

To Marinesco and others (1931) must be given the credit for recognizing a new syndrome and for providing the only histological studies at present available. They observed that the syndrome con- sisted of cataract, oligophrenia, and a neurological picture including both cerebellar and pyramidal features. They also noticed that the affected persons were undersized. Though commenting on skeletal anomalies, they attributed these, probably incorrectly, to rickets, and their views as to aetiology in general are quite unacceptable.

To Sjögren (1950) is to be given the credit for recognizing this syndrome for the second time and for realizing for the first time that it resulted from a single autosomal recessive gene. It would, however, be unfortunate if Sjögren's name were applied to this syndrome as an eponym since an entirely different disorder is already accepted in current literature under this eponymous title (Sjögren, 1933).

We have been unable to trace any other examples of this syndrome in the world's medical writings, nor are Professor Arnold Sorsby (1952) and Dr. Julia Bell (1952) familiar with any other records. Having discarded the cases reported by Richards (1950) we are reduced to the discussion of 20 persons, four from Roumania, 14 from Sweden, and two of our own. This discussion must be divided into two parts because important details of the pedigree are lacking in the Roumanian family and only four of the 14 Swedish examples had been examined, so that the genetics of the syndrome can only be related to 16 of the patients and the clinical syndrome to 10 .

Sjögren pointed out that five out of six of his sibships containing affected persons were the result of first cousin marriages, or $83 \pm 17 \%$. One of our own sibships $(\mathrm{V}, 1-9)$ is the result of a marriage which can be considered as equivalent to that of first cousins ; in the second $(\mathrm{V}, 10-16)$ the relationship is more distant. Hence, adding our figures to those of Sjögren, six out of eight of the sibships have resulted from first cousin marriages, or $75 \pm 16 \%$, and seven out of eight have resulted from consanguineous marriages, or $88 \pm 14 \%$.

It is well known that the rarer a recessive gene the more frequently is there a history of consanguinity in the parents of affected persons, and on this basis it would seem that the syndrome under discussion results from one of the rarest known recessive genes in man.

From the available clinical evidence the total syndrome appears to be as follows. Of the 20 affected persons eight were males and 12 were females. The first recognizable features have usually been the cerebellar ataxia, though cataract was detected in some at an early age. The mental defect has probably never been of the most serious order and it is not surprising that it was often not 
recognized until adult life, though Marinesco and others (1931) suggested that in their patients the defect was detected at an early age. Still later has it become apparent that these persons are always undersized. Details relating to the cataract are not always available though it would seem clear that in some the cataract is evident in early childhood, that it probably always progresses to complete blindness, but the age at which blindness appears varies considerably from early childhood to young adult life. The skeletal anomalies are usually of a minor kind but include kyphoscoliosis, genu valgum, deformities of the digits, and talipes. There is no suggestion that the oligophrenia is progressive, and only scanty evidence that the degree of ataxia increases. There is clinical evidence in several recorded patients of involvement of the pyramidal system and, although the total disability may not have increased, the plantar responses in some patients have become extensor with the passage of time. There has been no previous reference to the cardiovascular system, but it is probably significant that both our patients were suffering from vascular hypertension in young adult life.

Genetic disorders in man are known to affect particularly the central nervous system, the eye, and the skin, often all three together, and it may be noted that in none of the 20 recorded patients has there been any skin lesion. With all gross brain disorders epilepsy is frequent but, on the available evidence, one affected person had a single fit, and one developed epilepsy at 28 , though in three siblings of another affected person death occurred from infantile convulsions. There is, at present, nothing to suggest that this disorder shortens the length of life, nor are we aware of any post-mortem studies.

\section{Summary and Conclusions}

An extremely rare hereditary syndrome is described, determined by a single autosomal recessive gene, the incidence of consanguinity in the parents being very high.

The syndrome consists of congenital and stationary cerebellar ataxia, often with evidence of involvement of the pyramidal system; oligophrenia of moderate degree; cataract which appears in childhood and progresses to blindness; multiple minor skeletal anomalies, all the patients being undersized; and in some patients vascular hypertension.

Two new examples are discussed.
We wish to thank Professor C. W. Vining for first calling our attention to the patients described, and to Dr. J. A. Fraser Roberts for his invaluable help and criticism.

\section{REFERENCES}

Bell, J. (1952). Personal communication. Marinesco, G., Draganesco, S., and Vasiliu, D. (1931). Encéphale, 26, 97.

Richards, B. W. (1950). J. ment. Sci., 96, 537.

Sjögren, H. (1933). Acta ophthal., Kbh., Suppl. 2. 286. Sjogren, T. (1947). Acta psychiat., Kbh., Sup Sorsby, A. (1952). Personal communication.

\section{Addendum}

Since submitting this paper Professor T. Sjögren has drawn our attention to a report by Gursdorf, Hecaen, and Nau-Massonnet (1952). They describe a girl of 16 suffering from epilepsy and a neurological syndrome, with cerebellar and pyra- $\vec{\circ}$ midal components; she was also mentally backward. This girl, however, was tall and had no cataract. The electro-encephalogram showed changes in keeping with acquired epilepsy. She had had to be revived at birth because of strangulation by the cord and radiographs showed congenitat asymmetry of the skull. The mother had had threo miscarriages and seven normal pregnancies, and o the latter the patient was the fourth. The secon ${ }^{\circ}$. (male, aged 20) had bilateral congenital cataract, left cerebellar syndrome, was dull and backward 3 and had had convulsions in infancy. The thirg (male, aged 18) had congenital cataract, and the fifth (female, age not mentioned) also had congenit cataract and had had infantile convulsions. Further, the mother had congenital cataract and it was known to exist in other members of her family. Whether her marriage was consanguineous is not mentioned.

It will be seen that this family includes a number of abnormal persons amongst whom are found all $\overline{\bar{O}}$ the components of the syndrome we are discussing, but there is not one affected person showing the $\rightleftharpoons$ complete syndrome and we doubt very much whether it is the same condition; indeed the authors themselves are in some doubt though they appear to incline to the view that this family displays a forme fruste. It is unfortunate, for reasons previously mentioned, that they have called this "Sjögren's $\delta$ syndrome", and this is indeed the reason why we overlooked this paper.

Gursdorf, C., Hecaen, H., and Nau-Massonnet, M. (1952). Ann. I med.psych., 1, 65 . 